\title{
Coagulopathy in patients with COVID-19: a systematic review and meta-analysis
}

\author{
Xiaolin Zhang ${ }^{1, *}$, Xue Yang ${ }^{1,},{ }^{*}$ Hongmei Jiao ${ }^{1}$, Xinmin Liu ${ }^{1}$ \\ ${ }^{1}$ Department of Geriatrics, Peking University First Hospital, Beijing 100034, China \\ *Equal contribution
}

Correspondence to: Xinmin Liu; email: Ixm2128@163.com, https://orcid.org/0000-0002-3264-5255

Keywords: coronavirus, COVID-19, disease severity, coagulation, coagulopathy

Received: June 16, 2020

Accepted: September 20, 2020

Published: November 24, 2020

Copyright: (c) 2020 Zhang et al. This is an open access article distributed under the terms of the Creative Commons Attribution License (CC BY 3.0), which permits unrestricted use, distribution, and reproduction in any medium, provided the original author and source are credited.

\begin{abstract}
COVID-19 patients frequently exhibit coagulation abnormalities and thrombotic events. In this meta-analysis, we investigated the association between coagulopathy and the severity of COVID-19 illness. Using PubMed, Embase, Cochrane, WanFang Database, CNKI, and medRxiv, a systematic literature search was conducted for studies published between December 1, 2019 and May 1, 2020. We then analyzed coagulation parameters in COVID-19 patients exhibiting less severe and more severe symptoms. All statistical analyses were performed using Stata14.0 software. A total of 3,952 confirmed COVID-19 patients from 25 studies were included in the meta-analysis. Patients with severe symptoms exhibited higher levels of D-dimer, prothrombin time (PT), and fibrinogen (FIB) than patients with less severe symptoms (SMD 0.83, 95\% Cl: 0.70-0.97, $\mathrm{I}^{2}$ 56.9\%; SMD 0.39, 95\% Cl: 0.14-0.64, $\mathrm{I}^{2}$ 79.4\%; and SMD 0.35, 95\% Cl: 0.17-0.53, $\mathrm{I}^{2} 42.4 \%$, respectively). However, platelet and activated partial thromboplastin times did not differ (SMD $-0.26,95 \% \mathrm{Cl}$ : $-0.56-0.05, I^{2} 82.2 \%$; and SMD -0.14, 95\% Cl: -0.45-0.18, $I^{2} 75.7 \%$, respectively). These findings demonstrate that hypercoagulable coagulopathy is associated with the severity of COVID-19 symptoms and that D-dimer, PT, and FIB values are the main parameters that should be considered when evaluating coagulopathy in COVID-19 patients.
\end{abstract}

\section{INTRODUCTION}

Coronavirus Disease 2019 (COVID-19) is a viral respiratory infection caused by the 2019 novel coronavirus. As of May 22, 2020, a total of 5,061,476 confirmed cases with 331,475 deaths have been reported globally since the COVID-19 outbreak [1]. Thus, the World Health Organization (WHO) declared the disease a global pandemic. After SARS and MERS, COVID-19 is the third most lethal zoonotic coronavirus disease that occurred in the last two decades [2]; however, it has caused many more deaths than SARS or MERS [3]. Due to the extremely high mortality rate of COVID-19, there is an urgent need to identify the clinical features associated with its progression.
Coagulopathy and thrombotic events are serious complications that occur in some COVID-19 patients. A recent study has reported that the COVID-19 associated coagulopathy is characterized by increased levels of prothrombin time (PT), activated partial thromboplastin time (APTT), and D-dimer [4]. In addition, several studies have shown that elevated D-dimer levels are associated with in-hospital mortality $[5,6]$. Recent autopsy reports from the United States have demonstrated that in addition to lung injuries, severe COVID-19 patients exhibit a hypercoagulable state evidenced by thrombotic events in the lung, kidney, and possibly in the heart and other organs [7]. However, whether coagulopathy is associated with the severity of COVID-19 illness remains unclear. Therefore, we conducted a systematic review and meta-analysis by 
incorporating both English and Chinese published studies to investigate the role of coagulation dysfunction in the severity of COVID-19 progression.

\section{RESULTS}

\section{Selection of COVID-19 studies}

The detailed steps of literature search are highlighted in the flow diagram (Figure 1). Using different search strategies and six different databases, 1,967 COVID-19 articles were identified. After eliminating duplicate records, 1,132 articles were obtained. In addition, 776 articles were excluded because they were not original studies or were irrelevant to our meta-analysis. Full texts of the remaining 356 articles were assessed for eligibility, out of which 322 articles were eliminated because they did not meet the exclusion criteria. A total of 34 articles were included in the quality evaluation (Supplementary Table 2), out of which 9 articles were excluded due to a low quality (NOS $<5)$. Finally, 25 articles (1 in Chinese and 24 in English) were selected for the analyses $[6,8-31]$. The overall quality of the selected studies was moderate to high, with NOS scores ranging from 5-7.

\section{Characteristics of the included studies}

Data from 3,952 patients in the 25 included studies were used to analyze coagulation parameters in less severe and more severe COVID-19 patients. Notably, 23 studies were conducted in China (11 in Wuhan and 12 in other cities), 1 in Mexico, and 1 in the USA. All studies were retrospective observational studies; sample size varied from 21 to 577 . The median age ranged between 46 and 60 years, and the proportion of male patients ranged between $35.3 \%$ and $81.0 \%$. Twenty studies followed clinical guidelines (including trial version 4 , trial version 5 , trial version $7,6^{\text {th }}$ edition guidelines, $7^{\text {th }}$ edition guidelines, and WHO interim guideline) to evaluate the disease severity. However, two studies considered whether patients experienced ARDS, and one study considered whether patients underwent ICU care to judge the disease severity. The patient characteristics and demographic data for the included studies are shown in Supplementary Table 3.

\section{Coagulation parameters in less severe and more severe COVID-19 cases}

The values of D-dimer, platelets (PLT), prothrombin time (PT), activated partial thromboplastin time (APTT), and fibrinogen (FIB) were available in 25, 13, 13,9 , and 5 studies, respectively. We used the randomeffects model due to significant heterogeneity of Ddimer, PLT, PT, and APTT values. D-dimer and PT values were significantly higher in more severe patients than in less severe patients (SMD 0.83, 95\% CI: 0.70$0.97, \mathrm{I}^{2}: 56.9 \%$; and SMD: $0.39,95 \%$ CI: $0.14-0.64, \mathrm{I}^{2}$ : $79.4 \%$, respectively). The fixed-effects model was used due to insignificant heterogeneity of FIB values. Patients with more severe pneumonia exhibited significantly higher FIB values compared to less severe patients (SMD: 0.35, 95\% CI: 0.17-0.53, I ${ }^{2}: 42.4 \%$ ). However, no significant difference was observed in PLT and APTT values between severe and mild patients (SMD: $-0.26,95 \%$ CI: $-0.56-0.05, \mathrm{I}^{2}: 82.2 \%$; and SMD: -0.14 , 95\% CI: $-0.45-0.18, \mathrm{I}^{2}: 75.7 \%$, respectively). A forest plot of the coagulation parameters is shown in Figures 2 and 3. Details of the meta-analysis are highlighted in Table 1.

\section{Subgroup analysis}

Based on location, severity criteria, and patient age (the median age above and below 50), we conducted a subgroup analysis to determine the sources of heterogeneity. The results of subgroup analysis are presented in Table 2. Notably, the heterogeneity was significant in the subgroup analyses. However, the subgroup analyses did not explain the observed heterogeneity of D-dimer, PLT, PT, and APTT values.

\section{Sensitivity analysis and publication bias}

Sensitivity analysis showed that the pooled results were not sensitive to any individual study, thus validating the robustness of the study findings. Detailed results of sensitivity analysis are shown in Supplementary Figure 1. In addition, we assessed publication bias using the funnel plots and Egger's regression test. There was no significant publication bias among the APTT, D-dimer, FIB, PLT, and PT values in our study (Egger test: $\mathrm{P}=$ $0.236, \mathrm{P}=0.556, \mathrm{P}=0.289, \mathrm{P}=0.308, \mathrm{P}=0.534$, respectively). The funnel diagram and Egger's test are shown in Figure 4.

\section{DISCUSSION}

Our study demonstrates that coagulopathy is associated with the severity of COVID-19 symptoms, and that the more severe COVID-19 cases are characterized by significantly elevated levels of D-dimer, PT, and FIB. These findings are consistent with conclusions from a previous meta-analysis, which found that PT and Ddimer values were significantly increased in more severe COVID-19 cases [32]. However, we observed no significant decrease in the levels of PLT in severe COVID-19 cases. This observation differs from a previous meta-analysis that included only nine studies, and showed a considerable heterogeneity, possibly leading to unstable results [33]. 


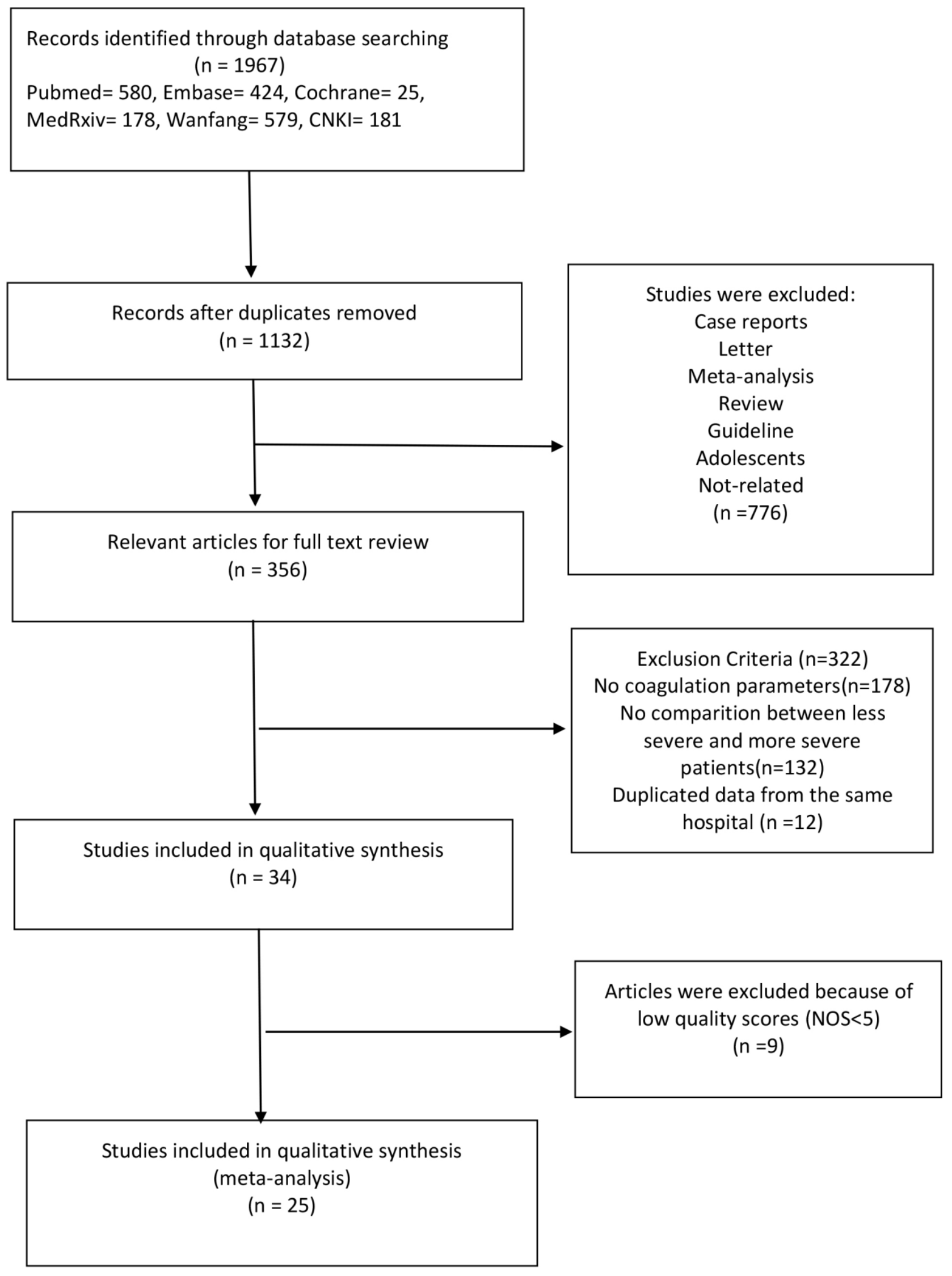

Figure 1. Schema of literature search. 


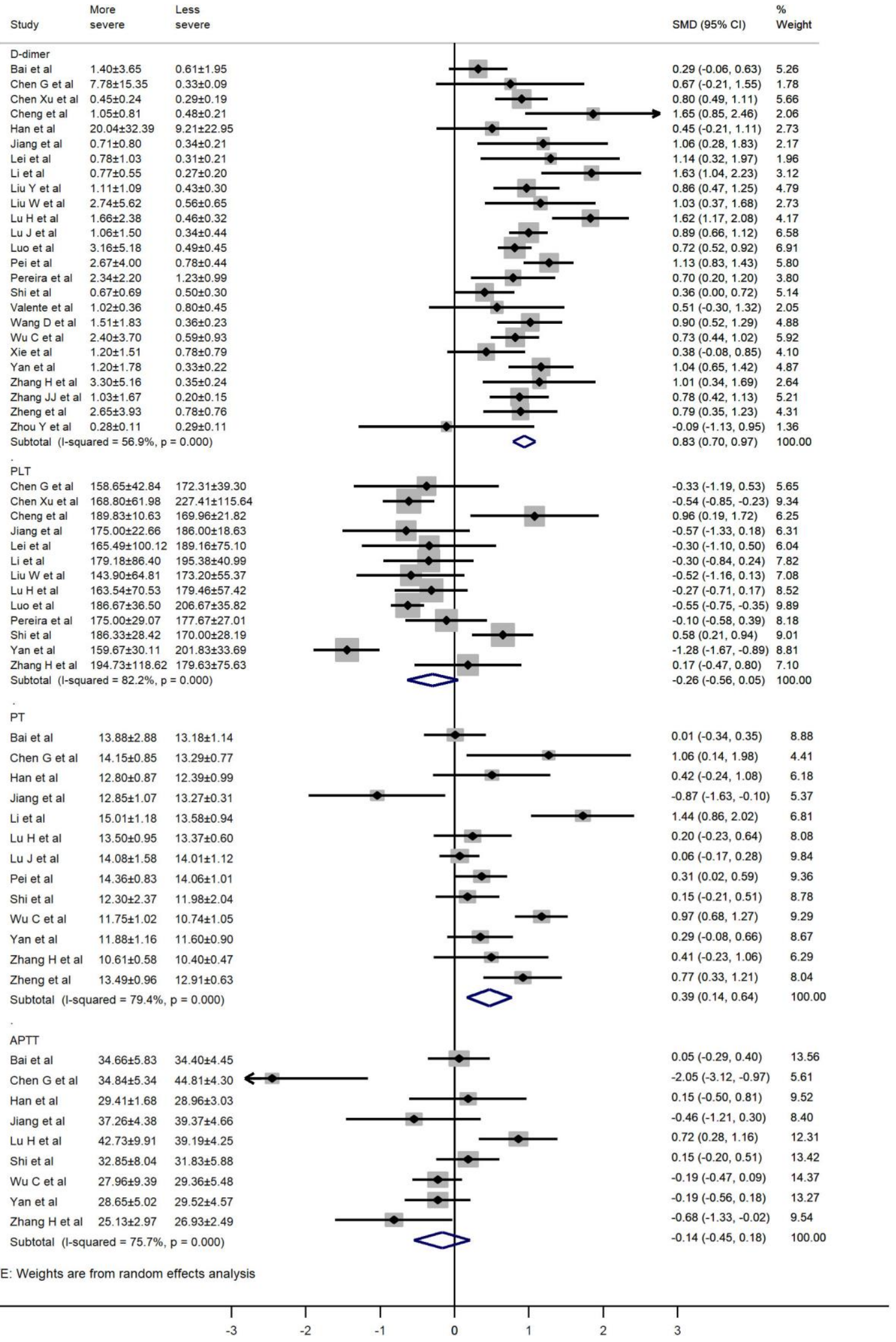

Figure 2. Forest plot of the association between D-dimer, PLT, PT, and APTT in patients with COVID-19 stratified by disease severity. 
The increased levels of D-dimer and PT indicate that the fibrinolytic system is activated in severely ill COVID-19 patients. The coagulation cascade is activated in response to viral infections as a host defense mechanism to limit the spread of pathogens. Additionally, increased cytokine release during viral infections stimulates pro-coagulant reactions resulting in coagulation. Furthermore, endothelial cell activation and damage may alter the natural antithrombotic state, given the tropism of the virus for ACE2 receptors [34]. COVID-19 associated coagulopathy (CAC) describes the pro-thrombotic properties in infected patients [35]. Although coagulopathy is reminiscent of disseminated intravascular coagulation (DIC), CAC does not cause clinical bleeding, and is thus distinct from DIC [36]. Clinical observations show that CAC is characterized by elevated fibrinogen, and nearly normal platelet counts [36]; these findings are consistent with our data. This can be explained by extramedullary megakaryocytes within the microvessels that have been detected by autopsy of COVID-19 patients [37]. The megakaryocytes can actively produce platelets within the peripheral circulation [38].
Previous studies have shown that the levels of PT and D-dimer are significantly increased in COVID-19 patients with more severe symptoms, but few studies have analyzed the fibrinogen levels. To our knowledge, this is the first meta-analysis that assessed the correlation between fibrinogen levels and the severity of COVID-19. Several studies have shown that the fibrinogen levels significantly increase during initial and progressive stages of viral infections, but this likely reflects a hypercoagulability instead of a consumptive coagulopathy. Furthermore, a recent study by Ranucci [39] reported comprehensive coagulation analyses on ICU admission with median fibrinogen levels of $7.8 \mathrm{~g} / \mathrm{L}$, and increased clot strength through thromboelastometry. SARS-CoV-2 infection often induces a cytokine storm that is dominated by interleukin-6 [40], which stimulates the fibrinogen synthesis. In addition, the variations in fibrinogen levels are dependent on the infection stage. Tang et al [41] reported that the fibrinogen levels decline during the late stages in COVID-19 non-survivors, despite their increased or normal levels on admission; this might be caused by sepsis-induced coagulopathy. Though very few COVID-19 studies have investigated the coagulation cascade in vitro, a related coronavirus,

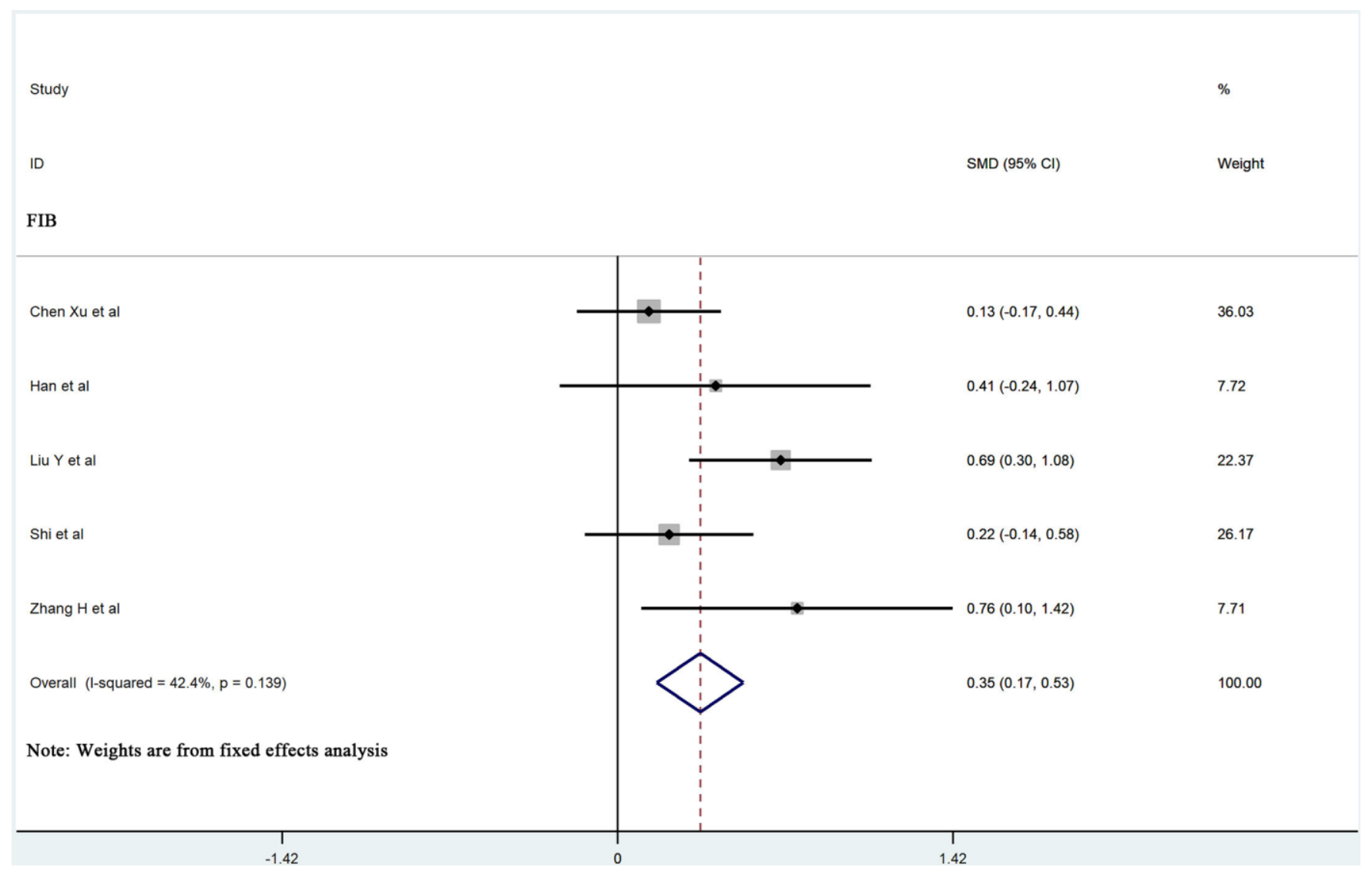

Figure 3. Forest plot of the association between FIB in patients with COVID-19 stratified by disease severity. 
Table 1. Summary of the meta-analysis results.

\begin{tabular}{|c|c|c|c|c|c|c|c|c|c|}
\hline \multirow[b]{2}{*}{ Groups } & \multirow[b]{2}{*}{ Studies } & \multicolumn{5}{|c|}{ Test of association } & \multicolumn{3}{|c|}{ Heterogeneity } \\
\hline & & SMD & $95 \% \mathrm{CI}$ & p value & Model & $\mathbf{Z}$ & Chi-squared & p value & $I^{2}(\%)$ \\
\hline D-dimer & 25 & 0.83 & $0.70,0.97$ & 0.000 & $\mathrm{RE}$ & 12.27 & 55.63 & 0.000 & 56.9 \\
\hline PLT & 13 & -0.26 & $-0.56,0.05$ & 0.096 & $\mathrm{RE}$ & 1.66 & 67.27 & 0.000 & 82.2 \\
\hline PT & 13 & 0.39 & $0.14,0.64$ & 0.002 & $\mathrm{RE}$ & 3.04 & 58.16 & 0.000 & 79.4 \\
\hline APTT & 9 & -0.14 & $-0.45,0.18$ & 0.384 & $\mathrm{RE}$ & 0.87 & 32.89 & 0.000 & 75.7 \\
\hline FIB & 5 & 0.35 & $0.17,0.53$ & 0.000 & $\mathrm{FE}$ & 3.75 & 6.94 & 0.139 & 42.4 \\
\hline \multicolumn{10}{|c|}{ RE, random effects } \\
\hline \multicolumn{10}{|c|}{ FE, fixed effects } \\
\hline \multicolumn{10}{|c|}{ SMD, standardized mean difference } \\
\hline \multicolumn{10}{|c|}{$\mathrm{CI}$, confidence interval } \\
\hline
\end{tabular}

Table 2. Results of subgroup meta-analyses.

\begin{tabular}{|c|c|c|c|c|c|c|c|}
\hline & & & No. of studies & SMD (95\% CI) & P-value & Heterogeneity $\mathbf{I}^{2}$ & $P$ value \\
\hline \multirow[t]{8}{*}{ D-dimer } & Criteria & Guidelines & 22 & $0.85(0.69,1.00)$ & 0.000 & 61.8 & 0.000 \\
\hline & & ARDS & 2 & $0.77(0.54,1.01)$ & 0.000 & 0 & 0.588 \\
\hline & & ICU care & 1 & $0.70(0.20,1.20)$ & 0.006 & Null & Null \\
\hline & Location & Wuhan & 12 & $0.76(0.62,0.89)$ & 0.000 & 42.1 & 0.061 \\
\hline & & $\begin{array}{l}\text { Other cities } \\
\text { in China }\end{array}$ & 11 & $1.01(0.72,1.30)$ & 0.000 & 69 & 0.000 \\
\hline & & $\begin{array}{l}\text { Other } \\
\text { countries }\end{array}$ & 2 & $0.65(0.22,1.07)$ & 0.003 & 0 & 0.692 \\
\hline & Age & $\geq 50$ & 13 & $0.72(0.57,0.86)$ & 0.031 & 48.2 & 0.026 \\
\hline & & $<50$ & 9 & $0.97(0.76,1.17)$ & 0.030 & 33.8 & 0.147 \\
\hline \multirow[t]{7}{*}{ PLT } & Criteria & Guidelines & 12 & $-0.27(0.60,0.06)$ & 0.104 & 83.3 & 0.000 \\
\hline & & ICU care & 1 & $-0.10(-0.59,0.39)$ & 0.699 & Null & Null \\
\hline & Location & Wuhan & 3 & $-0.54(-0.73,-0.35)$ & 0.000 & 0 & 0.884 \\
\hline & & $\begin{array}{l}\text { Other cities } \\
\text { in China }\end{array}$ & 9 & $-0.19(-0.65,0.26)$ & 0.407 & 87 & 0.000 \\
\hline & & $\begin{array}{l}\text { Other } \\
\text { countries }\end{array}$ & 1 & $-0.10(-0.58,0.39)$ & 0.699 & Null & Null \\
\hline & Age & $\geq 50$ & 5 & $-0.26(-0.65,0.14)$ & 0.281 & 92.1 & 0.000 \\
\hline & & $<50$ & 6 & $-0.34(-0.96,0.28)$ & 0.199 & 62.3 & 0.021 \\
\hline \multirow[t]{6}{*}{$\mathrm{PT}$} & Criteria & Guidelines & 12 & $0.36(0.13,0.59)$ & 0.002 & 69.6 & 0.000 \\
\hline & & ARDS & 1 & $0.91(0.68,1.27)$ & 0.000 & Null & Null \\
\hline & Location & Wuhan & 6 & $0.47(0.13,0.81)$ & 0.070 & 80.7 & 0.000 \\
\hline & & $\begin{array}{l}\text { Other cities } \\
\text { in China }\end{array}$ & 7 & $0.37(-0.03,0.76)$ & 0.068 & 78.8 & 0.000 \\
\hline & Age & $\geq 50$ & 6 & $0.47(0.17,0.76)$ & 0.002 & 72.9 & 0.002 \\
\hline & & $<50$ & 5 & $0.39(-0.22,1.00)$ & 0.214 & 87.7 & 0.000 \\
\hline
\end{tabular}




\begin{tabular}{ccccccc} 
APTT Criteria & Guidelines & 8 & $-0.15(0.53,0.23)$ & 0.432 & 77.8 & 0.000 \\
& ARDS & 1 & $-0.19(-0.47,0.09)$ & 0.185 & Null & Null \\
Location & Wuhan & 4 & $-0.30(-0.82,0.22)$ & 0.259 & 78.8 & 0.003 \\
& $\begin{array}{c}\text { Other cities } \\
\text { in China }\end{array}$ & 5 & $-0.04(-0.48,0.40)$ & 0.862 & 76.7 & 0.002 \\
Age & $\geq 50$ & 6 & $-0.15(-0.47,0.16)$ & 0.347 & 69.5 & 0.097 \\
& $<50$ & 1 & $-0.46(-1.12,0.30)$ & 0.236 & Null & Null \\
\hline
\end{tabular}

SARS-CoV-1, has been found to upregulate a panel of genes involved in coagulation, including fibrinogen [42].

Since abnormal coagulation parameters including elevated D-dimer and fibrin degradation products are associated with higher COVID-19 mortality rates, monitoring the coagulation parameters is immensely important for managing COVID-19. Zhou et al [5] conducted a study of 191 patients from Wuhan and found that D-dimer levels higher than $1 \mu \mathrm{g} / \mathrm{L}$ were associated with higher in-hospital mortality. WHO recently issued guidelines for managing COVID-19, and suggested that a great attention should be focused on coagulation dysfunction and thrombotic events [43].

Our findings suggest that dynamic monitoring of coagulation parameters in hospitalized COVID-19 patients is necessary for predicting COVID-19 progression with unfavorable outcome and early thrombotic events. Moreover, futures studies should determine whether early anticoagulation treatments, such as low molecular weight heparin (LMWH), warfarin, or new oral anticoagulant (NOAC) are beneficial in COVID-19 patients with significantly elevated coagulation parameters.

Regarding the limitations of our meta-analysis, there was a considerable heterogeneity among the included studies with respect to the definition of COVID-19 severity; both subgroup and sensitivity analyses could not identify the heterogeneity source. Some of the included studies did not use mean and standard deviation; rather, they gave estimates by median and quartile, which might have affected the heterogeneity. In addition, since some of the included studies did not describe all relevant patient characteristics, it was difficult to adjust for potentially confounding factors, such as comorbidity and treatment (including the use of anticoagulation or glucocorticoids). To maintain reliability of our conclusions, all low-quality studies were excluded. Finally, since retrospective studies were included in our meta-analysis, there was a risk of bias in the data collected.
In conclusion, our findings demonstrate that coagulopathy is associated with the severity of COVID19 illness. D-dimer, PT, and FIB values are important parameters for evaluating the coagulopathy in COVID19 patients. Since COVID-19 associated coagulopathy differs from disseminated intravascular coagulation, it is necessary to monitor closely the dynamics of coagulation parameters in COVID-19 patients.

\section{MATERIALS AND METHODS}

\section{Search strategy}

The protocol for this systematic review and metaanalysis has been registered in the International Platform of Registered Systematic Review and Metaanalysis Protocols (INPLSY) as INPLASY2020500049 (https://inplasy.com/). The articles included in the systematic review followed the Meta-analysis of Observational Studies in Epidemiology (MOOSE) guidelines (the checklist is shown in Supplementary Table 1), and were written in English and Chinese. The electronic databases Pubmed, Embase, Cochrane, WanFang Database, CNKI, and medRxiv were searched for reports published from December 1, 2019 to May 1, 2020, using a combination of the following keywords: "COVID-19" or "2019 novel coronavirus infection" or "SARS-CoV-2" and" characteristics" or" coagulopathy" or "coagulation". Besides, we screened and conducted a manual search of the references listed in each article to obtain comprehensive results. The search was done independently by two authors (Xiaolin Zhang and Xue Yang). A third investigator (Hongmei Jiao) assisted with the resolution of any contradicting search results.

\section{Inclusion and exclusion criteria}

The inclusion criteria were as follows: (1) Original studies focused on clinical characteristics of patients with COVID-19 including observational studies, casecontrol studies, cohort studies, and randomized control studies; (2) patients were categorized into less and more severe groups; (3) the coagulation parameters between groups were described. Exclusion criteria were as follows: (1) Non-original studies including 
A

APTT

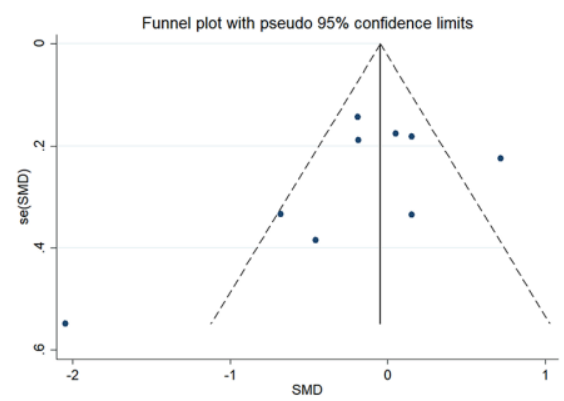

B

D-dimer

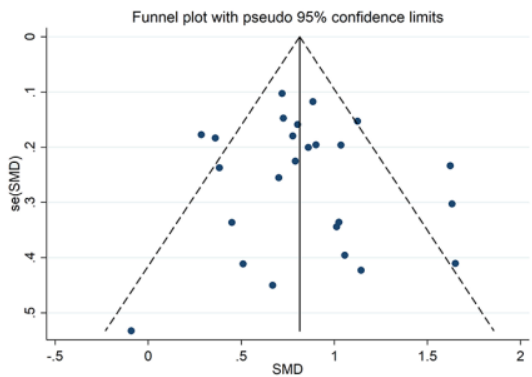

C

FIB

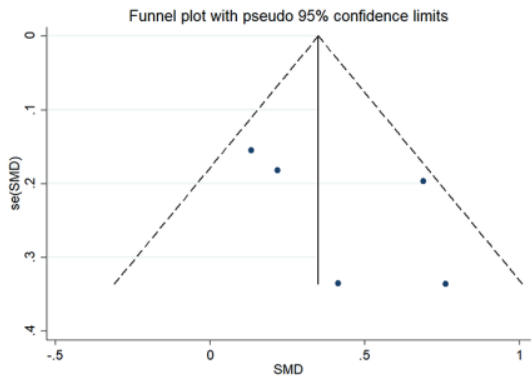

D

PLT

E

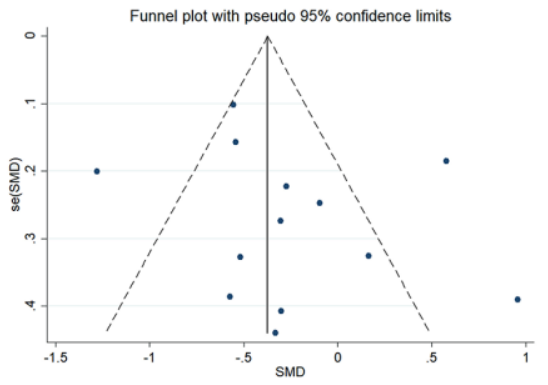

PT

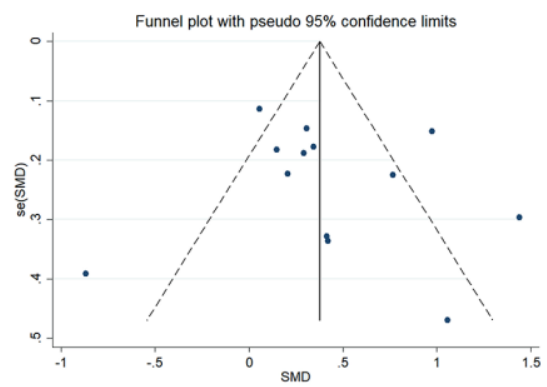

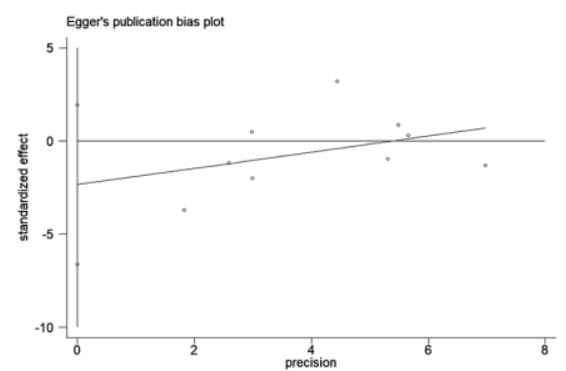

Egger's test $P=0.236$

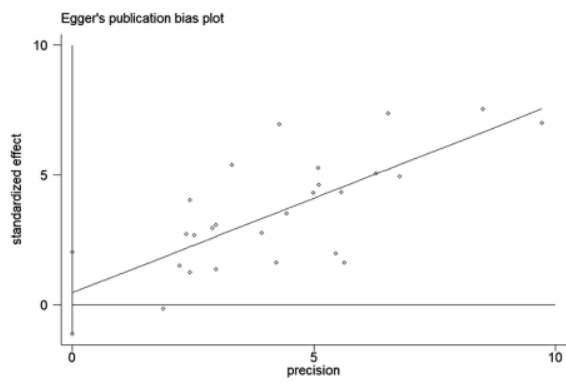

Egger's test $P=0.556$

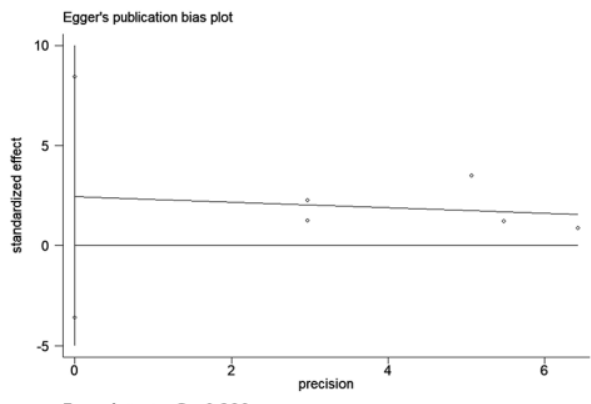

Egger's test $P=\mathbf{0 . 2 8 9}$

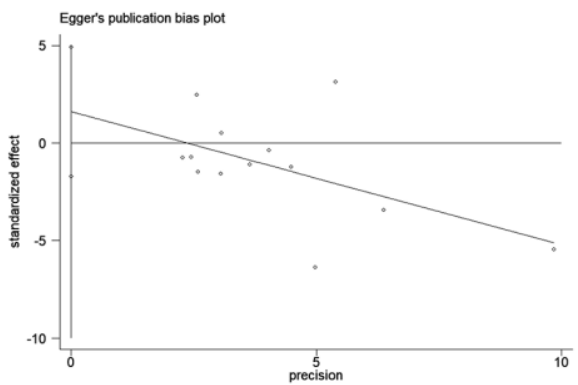

Egger's test $\quad P=0.308$

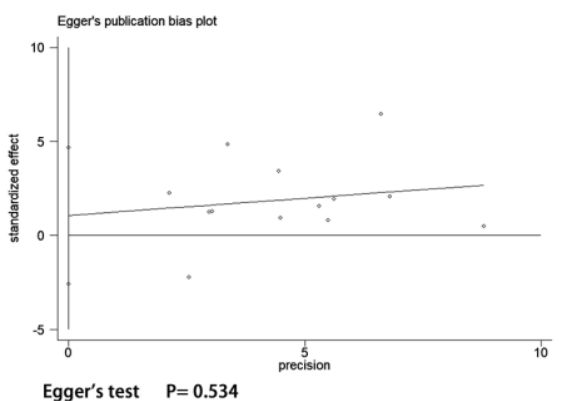

Figure 4. Funnel plot and Egger's test evaluating the publication bias of (A) APTT, (B) D-dimer, (C) FIB, (D) PLT, and (E) PT. 
commentaries, editorials, case reports, letters, metaanalysis, guidelines, and family-based studies; (2) same patients were enrolled in different studies; (3) patients were below 18 years old.

\section{Data extraction and quality assessment}

Two investigators (Xiaolin Zhang and Xue Yang) independently extracted the data and evaluated their quality. Contradicting conclusions from the two investigators were resolved by a third investigator (Hongmei Jiao) or through a common consensus. Data extracted from each study included the study characteristics, demographic information, and the outcomes. We used the Newcastle-Ottawa scale (NOS), which included patient selection, study comparability, and three components of outcomes assessment to evaluate the quality of the original study. Low-quality articles $(\mathrm{NOS}<5)$ were excluded from this metaanalysis.

\section{Data analysis}

All statistical analyses were performed via Stata 14.0 (Stata, College Station, TX, USA). For continuous variables, we calculated the standard mean difference (SMD) and the 95\%CI. Heterogeneity among the studies was assessed using the Chi-squared and $\mathrm{I}^{2}$ tests. For studies that reported only median and range, CI, or interquartile range, we estimated means and SDs as described by Wan [43]. A random-effects model was used when either $\mathrm{P}<0.05$ or $\mathrm{I}^{2}>50 \%$ defined significant heterogeneity across the articles. Otherwise, we used the fixed-effects model. A p-value of less than 0.05 was considered significant. Sensitivity analysis was conducted to evaluate the stability of the results and determine the effect of individual study on pooled results. Evidence of publication bias was examined using Egger's regression test for funnel asymmetry in addition to the visual inspection of funnel plots.

\section{Abbreviations}

ACE2: Angiotensin-Converting Enzyme 2; APTT: Activated partial thromboplastin time; ARDS: Acute respiratory distress syndrome; CAC: COVID-19 associated coagulopathy; CI: Confidence interval; COVID-19: Coronavirus disease 2019; DIC: Disseminated intravascular coagulation; FIB: Fibrinogen; LMWH: Low molecular weight heparin; MERS: Middle East Respiratory Syndrome; NOAC: New oral anticoagulant; PLT: Platelet; PT: Prothrombin time; SARS: Severe Acute Respiratory Syndrome ; SARS-CoV-2: Severe Acute Respiratory Syndrome Coronavirus 2; SD: Standard deviation; SMD: Standard mean difference; WHO: World Health Organization.

\section{AUTHOR CONTRIBUTIONS}

Study conception and design: Xiaolin Zhang. Data acquisition: Xiaolin Zhang, Xue Yang. Statistical analysis: Xiaolin Zhang. Interpretation of the data: Xiaolin Zhang, Xue Yang. Drafting of the manuscript: all authors. Critical revision of the manuscript for important intellectual content: all authors. Final approval of the manuscript: all authors.

\section{CONFLICTS OF INTEREST}

Xiaolin Zhang, Xue Yang, Hongmei Jiao, Xinmin Liu declare that they have no conflicts of interests.

\section{FUNDING}

This work was supported by the Scientific Research Seed Fund of Peking University First Hospital (Grant No. 2018SF058).

\section{REFERENCES}

1. World Health Organization. WHO Coronavirus Disease (COVID-19) Dashboard. 2020. https://who.sprinklr.com/

2. Ksiazek TG, Erdman D, Goldsmith CS, Zaki SR, Peret T, Emery S, Tong S, Urbani C, Comer JA, Lim W, Rollin PE, Dowell SF, Ling $A E$, et al, and SARS Working Group. A novel coronavirus associated with severe acute respiratory syndrome. N Engl J Med. 2003; 348:1953-66. https://doi.org/10.1056/NEJMoa030781 PMID: 12690092

3. Liu Y, Gayle AA, Wilder-Smith A, Rocklöv J. The reproductive number of COVID-19 is higher compared to SARS coronavirus. J Travel Med. 2020; 27:taaa021. https://doi.org/10.1093/jtm/taaa021 PMID: $\underline{32052846}$

4. Chen N, Zhou M, Dong X, Qu J, Gong F, Han Y, Qiu Y, Wang J, Liu Y, Wei Y, Xia J, Yu T, Zhang X, Zhang L. Epidemiological and clinical characteristics of 99 cases of 2019 novel coronavirus pneumonia in Wuhan, China: a descriptive study. Lancet. 2020; 395:507-13. https://doi.org/10.1016/S0140-6736(20)30211-7 PMID: $\underline{32007143}$

5. Zhou F, Yu T, Du R, Fan G, Liu Y, Liu Z, Xiang J, Wang Y, Song B, Gu X, Guan L, Wei Y, Li H, et al. Clinical course and risk factors for mortality of adult inpatients with COVID-19 in Wuhan, China: a retrospective cohort study. Lancet. 2020; 395:1054-62. https://doi.org/10.1016/S0140-6736(20)30566-3 PMID:32171076

6. Wu C, Chen X, Cai Y, Xia J, Zhou X, Xu S, Huang H, Zhang L, Zhou X, Du C, Zhang Y, Song J, Wang S, et al. Risk 
factors associated with acute respiratory distress syndrome and death in patients with coronavirus disease 2019 pneumonia in Wuhan, China. JAMA Intern Med. 2020; 180:934-43.

https://doi.org/10.1001/jamainternmed.2020.0994

PMID:32167524

7. Buja LM, Wolf DA, Zhao B, Akkanti B, McDonald M, Lelenwa L, Reilly N, Ottaviani G, Elghetany MT, Trujillo DO, Aisenberg GM, Madjid M, Kar B. The emerging spectrum of cardiopulmonary pathology of the coronavirus disease 2019 (COVID-19): report of 3 autopsies from Houston, Texas, and review of autopsy findings from other United States cities. Cardiovasc Pathol. 2020; 48:107233.

https://doi.org/10.1016/j.carpath.2020.107233

PMID:32434133

8. Bai X, Fang C, Zhou Y, Bai S, Liu Z, Xia L, Chen Q, Xu Y, Xia T, Gong S, Xie X, Song D, Du R, et al. Predicting COVID-19 malignant progression with $\mathrm{Al}$ techniques. medRxiv. 2020. [Epub ahead of print].

https://doi.org/10.2139/ssrn.3557984

9. Chen G, Wu D, Guo W, Cao Y, Huang D, Wang H, Wang $\mathrm{T}$, Zhang $\mathrm{X}$, Chen $\mathrm{H}, \mathrm{Yu} \mathrm{H}$, Zhang $X$, Zhang M, Wu S, et al. Clinical and immunological features of severe and moderate coronavirus disease. 2019. J Clin Invest. 2020; 130:2620-29.

https://doi.org/10.1172/JCl137244

PMID:32217835

10. Chen X, Zheng F, Qing Y, Ding S, Yang D, Lei C, Yin Z, Zhou X, Jiang D, Zuo Q, He J, Lv J, Chen P, et al. Epidemiological and clinical features of 291 cases with coronavirus disease 2019 in areas adjacent to Hubei, China: a double-center observational study. medRxiv. 2020.

https://doi.org/10.1101/2020.03.03.20030353

11. Cheng Y, Zhou Y, Zhu M, Zha L, Lu Z, Ding Z, Yang J, Yang G. Eosinopenia Phenotype in Patients with Coronavirus Disease 2019: A Multi-center Retrospective Study from Anhui, China. medRxiv. 2020.

https://doi.org/10.1101/2020.04.22.20071050

12. Han $\mathrm{H}$, Yang L, Liu R, Liu F, Wu KL, Li J, Liu XH, Zhu CL. Prominent changes in blood coagulation of patients with SARS-CoV-2 infection. Clin Chem Lab Med. 2020; 58:1116-20.

https://doi.org/10.1515/cclm-2020-0188

PMID:32172226

13. Jiang $X$, Tao J, Wu H, Wang $Y$, Zhao $W$, Zhou $M$, Huang J, You Q, Meng H, Zhu F, Zhang X, Qian M, Qiu Y. Clinical features and management of severe COVID-19: A retrospective study in Wuxi, Jiangsu Province, China. medRxiv. 2020. [Epub ahead of print]. https://doi.org/10.1101/2020.04.10.20060335
14. Liu L, Gao JY, Hu W, Zhang X, Guo L, Liu C, Tang Y, Lang C, Mou F, Yi Z, Pei Q, Sun K, Xiang J, Xiao J. Clinical characteristics of 51 patients discharged from hospital with COVID-19 in Chongqing, China. medRxiv. 2020. [Epub ahead of print]. https://doi.org/10.1101/2020.02.20.20025536

15. Dan L, Yunzhu L, Peng H, Wenlong G, Shuanghua W, Qing Z, Jingli F. Clinical characteristics of 80 patients with COVID-19 in Zhuzhou City. Chin J Infect Control. 2020; 19:227-234.

16. Liu Y, Sun W, Li J, Chen L, Wang Y, Zhang L, Yu L. Clinical features and progression of acute respiratory distress syndrome in coronavirus disease 2019. medRxiv. 2020.

https://doi.org/10.1101/2020.02.17.20024166

17. Liu W, Tao ZW, Wang L, Yuan ML, Liu K, Zhou L, Wei S, Deng Y, Liu J, Liu HG, Yang M, Hu Y. Analysis of factors associated with disease outcomes in hospitalized patients with 2019 novel coronavirus disease. Chin Med J (Engl). 2020; 133:1032-38.

https://doi.org/10.1097/CM9.0000000000000775 PMID:32118640

18. Lu H, Ai J, Shen $Y$, Li Y, Li T, Zhou X, Zhang H, Zhang $Q$, Ling $Y$, Wang $S, Q u H$, Gao $Y, L i ~ Y$, et al. A descriptive study of the impact of diseases control and prevention on the epidemics dynamics and clinical features of SARS-CoV-2 outbreak in Shanghai, lessons learned for metropolis epidemics prevention. medRxiv. 2020. [Epub ahead of print]. https://doi.org/10.1101/2020.02.19.20025031

19. Lu J, Hu S, Fan R, Liu Z, Yin X, Wang Q, Lv Q, Cai Z, Li H, $\mathrm{Hu}$ Y, Han Y, Hu H, Gao W, et al. ACP risk grade: a simple mortality index for patients with confirmed or suspected severe acute respiratory syndrome coronavirus 2 disease (COVID-19) during the early stage of outbreak in Wuhan, China. medRxiv. 2020. [Epub ahead of print]. https://doi.org/10.1101/2020.02.20.20025510

20. Luo X, Xia H, Yang W, Wang B, Guo T, Xiong J, Jiang Z, Liu Y, Yan X, Zhou W, Ye L, Zhang B. Characteristics of patients with COVID-19 during epidemic ongoing outbreak in Wuhan, China. medRxiv. 2020. [Epub ahead of print]. https://doi.org/10.1101/2020.03.19.20033175

21. Pei G, Zhang Z, Peng J, Liu L, Zhang C, Yu C, Ma Z, Huang Y, Liu W, Yao Y, Zeng R, Xu G. Renal involvement and early prognosis in patients with COVID-19 pneumonia. J Am Soc Nephrol. 2020; 31:1157-65.

https://doi.org/10.1681/ASN.2020030276 PMID: $\underline{32345702}$

22. Pereira MR, Mohan S, Cohen DJ, Husain SA, Dube GK, Ratner LE, Arcasoy S, Aversa MM, Benvenuto L, 
Dadhania DM, Kapur S, Dove LM, Brown RS Jr, et al. COVID-19 in solid organ transplant recipients: initial report from the US epicenter. Am J Transplant. 2020; 20:1800-08.

https://doi.org/10.1111/ajt.15941

PMID:32330343

23. Shi $P$, Ren G, Yang J, Li Z, Deng $S$, Li M, Wang S, Xu X, Chen F, Li Y, Li C, Yang X, Xie Z, et al. Clinical characteristics of imported and second-generation COVID-19 cases outside Wuhan, China: A multicenter retrospective study. medRxiv. 2020. [Epub ahead of print].

https://doi.org/10.1101/2020.04.19.20071472

24. Valente-Acosta B, Hoyo-Ulloa I, Espinosa-Aguilar L, Mendoza-Aguilar R, Garcia-Guerrero J, Ontanon-Zurita D, Gomez-Gomez B, Fueyo-Rodriguez O, Vera-Zertuche JM, Anzola-Arias R, Jimenez-Ceja JV, Horta-Capinteyro D, Olvera-Guzman C, et al. COVID-19 severe pneumonia in Mexico City - First experience in a Mexican hospital. medRxiv. 2020. [Epub ahead of print].

https://doi.org/10.1101/2020.04.26.20080796

25. Wang D, Wang J, Jiang Q, Yang J, Li J, Gao C, Jiang H, Ge L, Liu Y. No Clear Benefit to the Use of Corticosteroid as Treatment in Adult Patients with Coronavirus Disease 2019 : A Retrospective Cohort Study. medRxiv. 2020. https://doi.org/10.1101/2020.04.21.20066258

26. Xie H, Zhao J, Lian N, Lin S, Xie Q, Zhuo H. Clinical characteristics of non-ICU hospitalized patients with coronavirus disease 2019 and liver injury: a retrospective study. Liver Int. 2020; 40:1321-26. https://doi.org/10.1111/liv.14449 PMID:32239591

27. Yan $S$, Song $X$, Lin F, Zhu H, Wang $X$, Li M, Ruan J, Lin C, Liu X, Wu Q, Luo Z, Fu W, Chen S, et al. Clinical Characteristics of Coronavirus Disease 2019 in Hainan, China. medRxiv. 2020. [Epub ahead of print]. https://doi.org/10.1101/2020.03.19.20038539

28. Zhang $\mathrm{H}$, Wang $\mathrm{X}$, Fu Z, Luo $\mathrm{M}$, Zhang Z, Zhang $\mathrm{K}$, He $\mathrm{Y}$, Wan D, Zhang L, Wang J, Yan X, Han M, Chen Y. Potential Factors for Prediction of Disease Severity of COVID-19 Patients. medRxiv. 2020. [Epub ahead of print].

https://doi.org/10.1101/2020.03.20.20039818

29. Zhang JJ, Dong $X$, Cao YY, Yuan YD, Yang YB, Yan YQ, Akdis CA, Gao YD. Clinical characteristics of 140 patients infected with SARS-CoV-2 in Wuhan, China. Allergy. 2020; 75:1730-41.

https://doi.org/10.1111/all.14238 PMID:32077115

30. Zheng $Y, X u H$, Yang $M$, Zeng $Y$, Chen $H$, Liu R, Li Q, Zhang N, Wang D. Epidemiological characteristics and clinical features of 32 critical and 67 noncritical cases of COVID-19 in chengdu. J Clin Virol. 2020; 127:104366. https://doi.org/10.1016/j.jcv.2020.104366 PMID:32302954

31. Zhou Y, Han T, Chen J, Hou C, Hua L, He S, Guo Y, Zhang S, Wang Y, Yuan J, Zhao C, Zhang J, Jia Q, et al. Clinical and autoimmune characteristics of severe and critical cases of COVID-19. Clin Transl Sci. 2020; 10:1111. https://doi.org/10.1111/cts.12805 PMID: $\underline{32315487}$

32. Xiong $M$, Liang $X$, Wei YD. Changes in blood coagulation in patients with severe coronavirus disease 2019 (COVID-19): a meta-analysis. Br J Haematol. 2020; 189:1050-52.

https://doi.org/10.1111/bjh.16725

PMID:32304581

33. Lippi G, Plebani M, Henry BM. Thrombocytopenia is associated with severe coronavirus disease 2019 (COVID-19) infections: a meta-analysis. Clin Chim Acta. 2020; 506:145-48.

https://doi.org/10.1016/i.cca.2020.03.022 PMID:32178975

34. Thachil J, Tang N, Gando S, Falanga A, Cattaneo M, Levi $\mathrm{M}$, Clark C, Iba T. ISTH interim guidance on recognition and management of coagulopathy in COVID-19. J Thromb Haemost. 2020; 18:1023-26. https://doi.org/10.1111/jth.14810 PMID:32338827

35. Becker RC. COVID-19 update: covid-19-associated coagulopathy. J Thromb Thrombolysis. 2020; 50:54-67. https://doi.org/10.1007/s11239-020-02134-3 PMID:32415579

36. Connors JM, Levy JH. COVID-19 and its implications for thrombosis and anticoagulation. Blood. 2020; 135:2033-40.

https://doi.org/10.1182/blood.2020006000 PMID:32339221

37. Fox SE, Akmatbekov A, Harbert JL, Li G, Quincy Brown J, Vander Heide RS. Pulmonary and cardiac pathology in African American patients with COVID-19: an autopsy series from New Orleans. Lancet Respir Med. 2020; 8:681-86.

https://doi.org/10.1016/S2213-2600(20)30243-5 PMID:32473124

38. Lefrançais E, Ortiz-Muñoz G, Caudrillier A, Mallavia B, Liu F, Sayah DM, Thornton EE, Headley MB, David T, Coughlin SR, Krummel MF, Leavitt AD, Passegué E, Looney MR. The lung is a site of platelet biogenesis and a reservoir for haematopoietic progenitors. Nature. 2017; 544:105-09.

https://doi.org/10.1038/nature21706 PMID:28329764

39. Ranucci M, Ballotta A, Di Dedda U, Bayshnikova E, Dei Poli M, Resta M, Falco M, Albano G, Menicanti L. The procoagulant pattern of patients with COVID-19 acute 
respiratory distress syndrome. J Thromb Haemost. 2020; 18:1747-51.

https://doi.org/10.1111/ith.14854 PMID:32302448

40. Bahrami M, Kamalinejad M, Latifi SA, Seif F, Dadmehr M. Cytokine storm in COVID-19 and parthenolide: preclinical evidence. Phytother Res. 2020; 34:2429-30. https://doi.org/10.1002/ptr.6776 PMID:32472655

41. Tang N, Li D, Wang X, Sun Z. Abnormal coagulation parameters are associated with poor prognosis in patients with novel coronavirus pneumonia. J Thromb Haemost. 2020; 18:844-47. https://doi.org/10.1111/jth.14768

PMID:32073213

42. World Health Organization. Clinical management of COVID-19: interim guidance. 2020.

43. Wan X, Wang W, Liu J, Tong T. Estimating the sample mean and standard deviation from the sample size, median, range and/or interquartile range. BMC Med Res Methodol. 2014; 14:135.

https://doi.org/10.1186/1471-2288-14-135

PMID:25524443 


\section{SUPPLEMENTARY MATERIALS}

\section{Supplementary Figure}

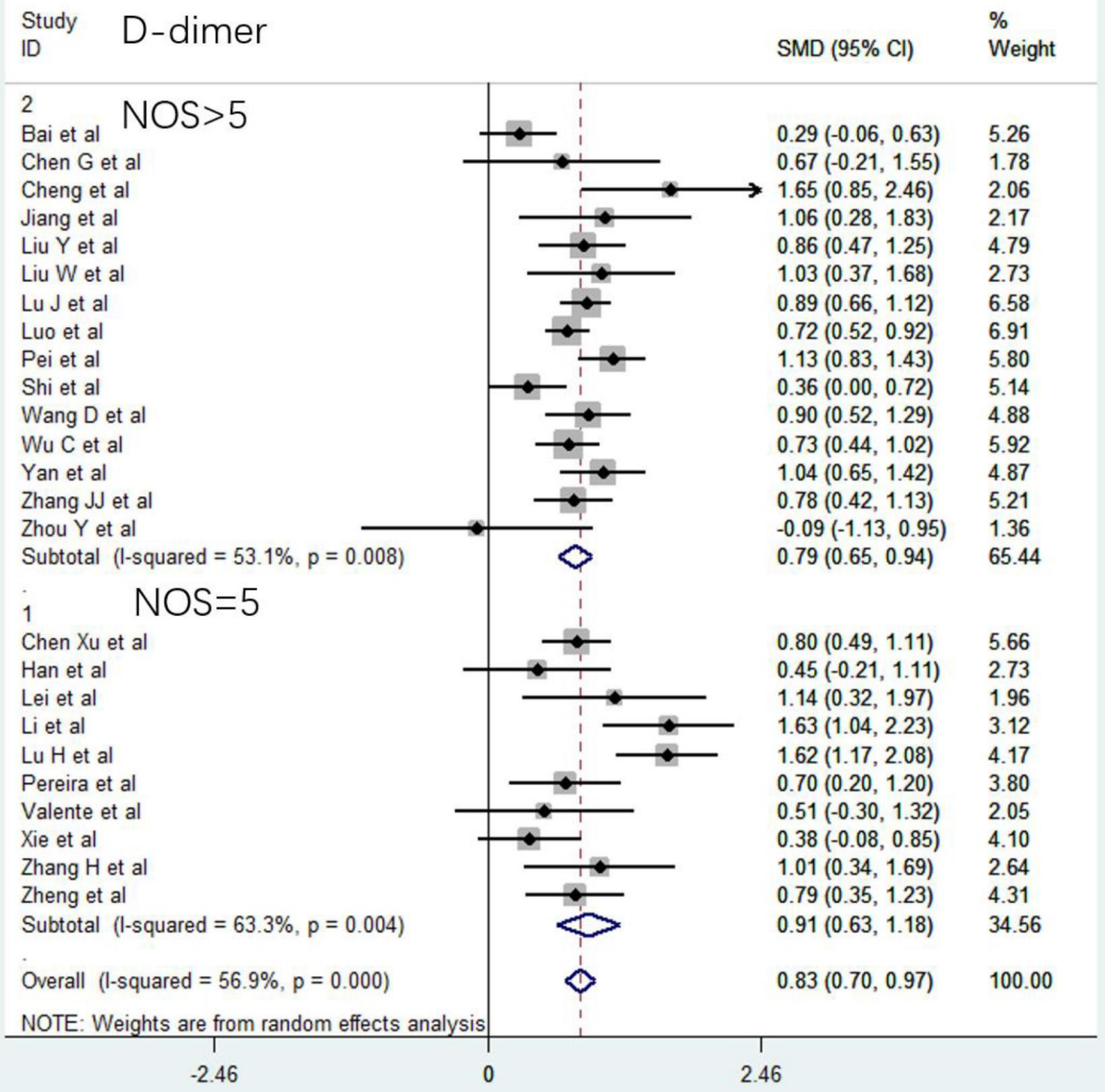



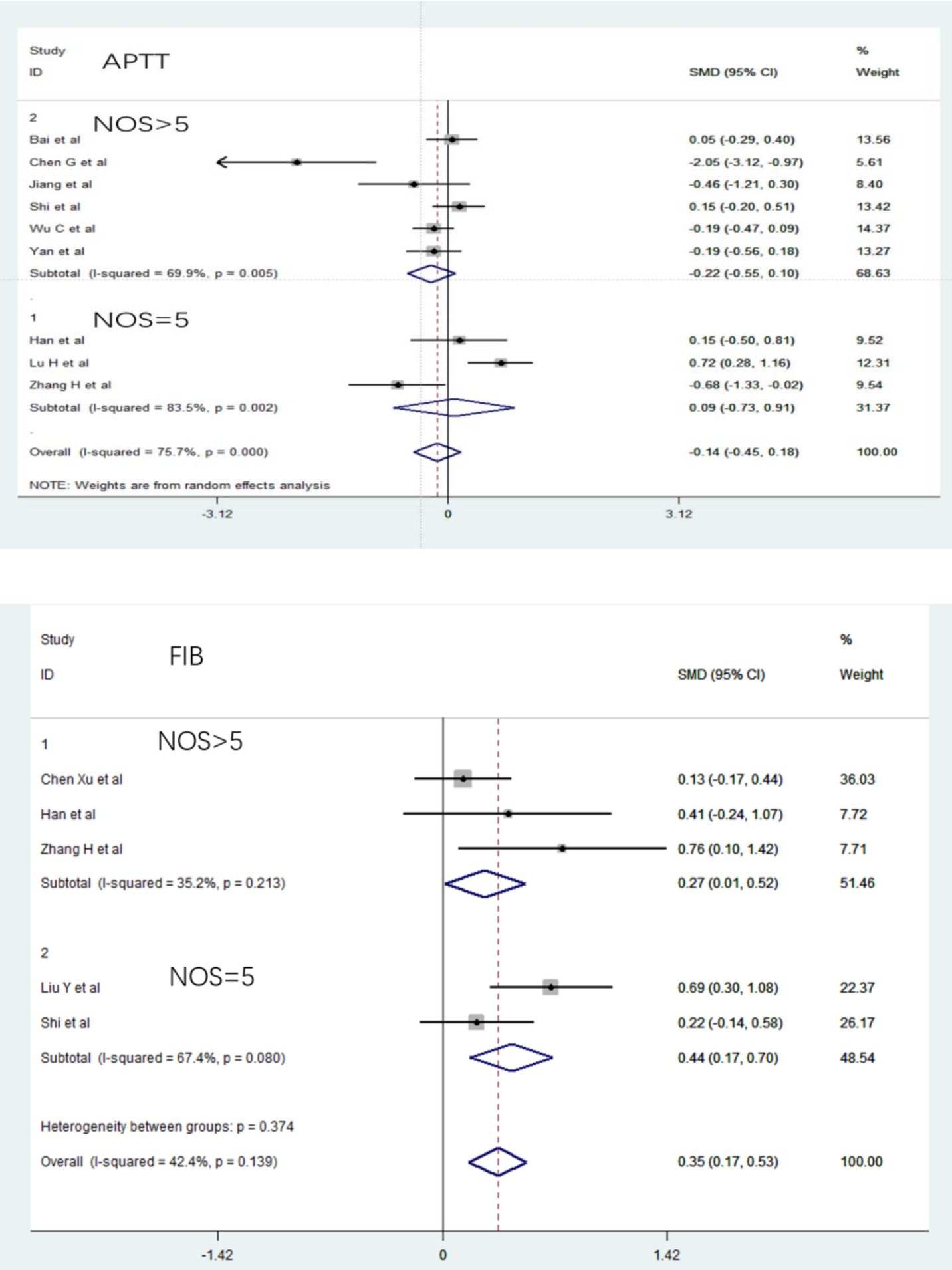

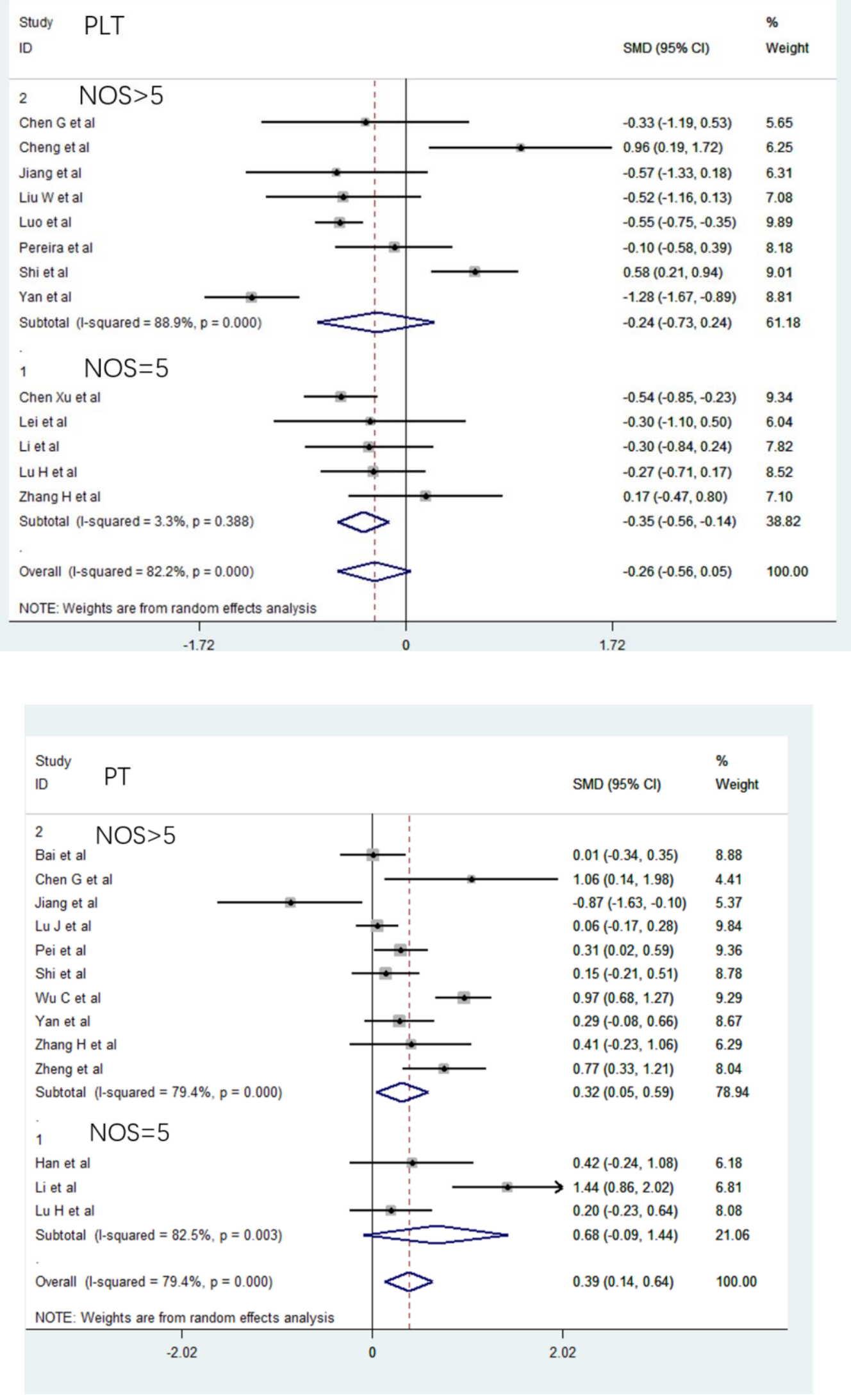

Supplementary Figure 1. Subgroup analyses of the association between D-dimer, PLT, PT, APTT in patients with COVID-19 stratified by disease severity according to NOS $>5$ and NOS $=5$. 


\section{Supplementary Tables}

Please browse Full Text version to see the data of Supplementary Tables 1 and 3.

Supplementary Table 1. MOOSE Checklist.

Supplementary Table 2. Results of quality assessment using Newcastle-Ottawa Scale for observational studies.

\begin{tabular}{|c|c|c|c|c|c|c|c|c|c|}
\hline \multirow[b]{2}{*}{ Study } & \multicolumn{4}{|c|}{ Selection } & \multirow{2}{*}{$\begin{array}{l}\text { Comparability } \\
\text { Comparability of } \\
\text { cases and controls } \\
\text { on the basis of the } \\
\text { design or analysis } \\
\end{array}$} & \multicolumn{3}{|c|}{ Exposure } & \multirow[b]{2}{*}{ scores } \\
\hline & $\begin{array}{c}\text { Is the } \\
\text { case } \\
\text { definition } \\
\text { adequate }\end{array}$ & $\begin{array}{l}\text { Representativeness } \\
\text { of the cases }\end{array}$ & $\begin{array}{l}\text { Selection } \\
\text { of } \\
\text { controls }\end{array}$ & $\begin{array}{c}\text { Definition } \\
\text { of } \\
\text { controls }\end{array}$ & & $\begin{array}{l}\text { Ascertainment } \\
\text { of exposure }\end{array}$ & $\begin{array}{c}\text { Same method } \\
\text { of } \\
\text { ascertainment } \\
\text { for cases and } \\
\text { controls } \\
\end{array}$ & $\begin{array}{l}\text { Non- } \\
\text { Response } \\
\text { rate }\end{array}$ & \\
\hline Bai et al & $\star$ & $\star$ & $\star$ & $\star$ & & & $\star$ & $\star$ & 6 \\
\hline $\begin{array}{l}\text { Chen } \mathrm{G} \\
\text { et al }\end{array}$ & $\star$ & $\star$ & $\star$ & $\star$ & & $\star$ & $\star$ & & 6 \\
\hline $\begin{array}{l}\text { Chen Xu } \\
\text { et al }\end{array}$ & $\star$ & $\star$ & $\star$ & $\star$ & & & $\star$ & & 5 \\
\hline Cheng et al & $\star$ & $\star$ & $\star$ & $\star$ & $\star$ & & $\star$ & & 6 \\
\hline Han et al & $\star$ & $\star$ & $\star$ & $\star$ & $\star$ & $\star$ & $\star$ & & 7 \\
\hline Jiang et al & $\star$ & $\star$ & $\star$ & $\star$ & & $\star$ & $\star$ & $\star$ & 7 \\
\hline Lei et al & $\star$ & $\star$ & $\star$ & $\star$ & $\star$ & & $\star$ & & 6 \\
\hline Li et al & $\star$ & $\star$ & $\star$ & $\star$ & $\star$ & $\star$ & $\star$ & & 7 \\
\hline Liu Y et al & $\star$ & $\star$ & $\star$ & $\star$ & $\star$ & $\star$ & $\star$ & & 7 \\
\hline Liu $\mathrm{W}$ et al & $\star$ & $\star$ & $\star$ & $\star$ & & $\star$ & $\star$ & & 6 \\
\hline Lu H et al & $\star$ & $\star$ & $\star$ & $\star$ & & & $\star$ & & 5 \\
\hline Lu J et al & $\star$ & $\star$ & $\star$ & $\star$ & $\star$ & & $\star$ & $\star$ & 7 \\
\hline Luo et al & $\star$ & $\star$ & $\star$ & $\star$ & $\star$ & & $\star$ & & 6 \\
\hline Pei et al & $\star$ & $\star$ & $\star$ & $\star$ & $\star$ & & $\star$ & & 6 \\
\hline $\begin{array}{l}\text { Pereira } \\
\text { et al }\end{array}$ & $\star$ & $\star$ & $\star$ & $\star$ & & & $\star$ & $\star$ & 6 \\
\hline Shi et al & $\star$ & $\star$ & $\star$ & $\star$ & & & $\star$ & $\star$ & 6 \\
\hline $\begin{array}{l}\text { Valente } \\
\text { et al }\end{array}$ & $\star$ & $\star$ & $\star$ & $\star$ & & & $\star$ & & 5 \\
\hline $\begin{array}{l}\text { Wang D } \\
\text { et al }\end{array}$ & $\star$ & $\star$ & $\star$ & $\star$ & $\star$ & & $\star$ & & 6 \\
\hline Wu C et al & $\star$ & $\star$ & $\star$ & $\star$ & $\star$ & & $\star$ & $\star$ & 6 \\
\hline Xie et al & $\star$ & $\star$ & $\star$ & $\star$ & $\star$ & & $\star$ & & 6 \\
\hline Yan et al & $\star$ & $\star$ & $\star$ & $\star$ & & & $\star$ & $\star$ & 6 \\
\hline $\begin{array}{l}\text { Zhang H } \\
\text { et al }\end{array}$ & $\star$ & $\star$ & $\star$ & $\star$ & & & $\star$ & & 5 \\
\hline $\begin{array}{l}\text { Zhang JJ } \\
\text { et al }\end{array}$ & $\star$ & $\star$ & $\star$ & $\star$ & & $\star$ & $\star$ & $\star$ & 7 \\
\hline Zheng et al & $\star$ & $\star$ & $\star$ & $\star$ & & & $\star$ & & 5 \\
\hline $\begin{array}{l}\text { Zhou Y } \\
\text { et al }\end{array}$ & $\star$ & $\star$ & $\star$ & $\star$ & & & $\star$ & & 5 \\
\hline
\end{tabular}




\begin{tabular}{|c|c|c|c|c|c|c|c|}
\hline Lei $\mathrm{S}$ et al & $\star$ & $\star$ & $\star$ & $\star$ & & & 4 \\
\hline $\begin{array}{l}\text { Dan W } \\
\text { et al }\end{array}$ & $\star$ & & $\star$ & $\star$ & & & 3 \\
\hline Cheng Q & $\star$ & $\star$ & $\star$ & $\star$ & & & 4 \\
\hline Wan S & $\star$ & $\star$ & $\star$ & $\star$ & & & 4 \\
\hline Huang $\mathrm{C}$ & $\star$ & & $\star$ & $\star$ & & $\star$ & 4 \\
\hline Liu M & $\star$ & $\star$ & $\star$ & $\star$ & & & 4 \\
\hline Cai $Q$ et al & $\star$ & $\star$ & & $\star$ & $\star$ & & 4 \\
\hline Zuo F et al & $\star$ & $\star$ & $\star$ & $\star$ & & & 4 \\
\hline $\begin{array}{l}\text { Zhan T } \\
\text { et al }\end{array}$ & $\star$ & $\star$ & $\star$ & $\star$ & & & 4 \\
\hline
\end{tabular}

Supplementary Table 3. Main characteristics of the included studies in meta-analysis. 